\title{
Augmenting the Transit Capacity of Delhi by Renewal of the Sub-Urban Railway
}

\author{
NISAR KHAN \\ Faculty of Architecture \& Ekistics, Jamia Millia Islamia, New Delhi - 110025, India \\ Email: nkhan2@jmi.ac.in
}

Received: December 21 $1^{\text {st }}, 2014$ | Revised: January 9 $9^{\text {th }}, 2015$ | Accepted: January $12^{\text {th }}, 2015$

Published online: January 21, 2015

The Author(s) 2015. This article is published with open access at www.chitkara.edu.in/publications

\begin{abstract}
This paper discusses the specific case of the untapped potential of the Sub-Urban Railway in Delhi. The Sub-Urban Railway, used as a passenger service during ASIAD Games of 1982 , lost its relevance in due course of time. Delhi commutes primarily through various public and private modes of road-based transportation, with the Delhi Metro emerging as an alternative. Urban transportation in Delhi is facing a crisis due to long traffic jams, rising numbers of vehicles on roads, environmental pollution, waste of energy, among others. Ironically, the existing infrastructure of the Sub-Urban Railway is left unutilized, though this may well provide increased passenger capacity to the Mega-City while simultaneously addressing the concerns of environment and energy as well. The paper is based on 3-year long study by the author of the salient aspects of the Sub-Urban Railway in Delhi and also the resultant detailed proposals for the augmentation of the city's Transport scenario.
\end{abstract}

Keywords: Delhi, Transit, Sub-Urban Railways, Renewal, Augmentation

\section{INTRODUCTION}

The megacity of Delhi is a nightmare for commuters and urban planners. The city, with a total geographical area of 148300 hectares and with a population exceeding 18 million dwellers, travels primarily via a network of roads using both public and private modes of transport (DDA, 2007). The number of vehicles in Delhi exceeds the combined total of vehicles in the other three mega cities of the country. There are about 16.6 million registered vehicles in Delhi and about 11.2 million vehicles in the NCR, the National Capital Region (Fig. 1). With an addition of more than 1500 cars every day, the roads are often choked, compromising the mobility, safety and ecology of the city (Delhi Traffic Police).

About 420 million man-hours are wasted daily in Delhi NCR while commuting from residence to workplace, simultaneously burning tons of fuel in traffic jams. Also, the roads of Delhi register highest causalities in road accidents in Urban India (Delhi Traffic Police).

Creative Space Vol. 2, No. 2, January 2015 pp. 183-196

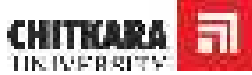

C2015 by Chitkara University. All Rights Reserved. 


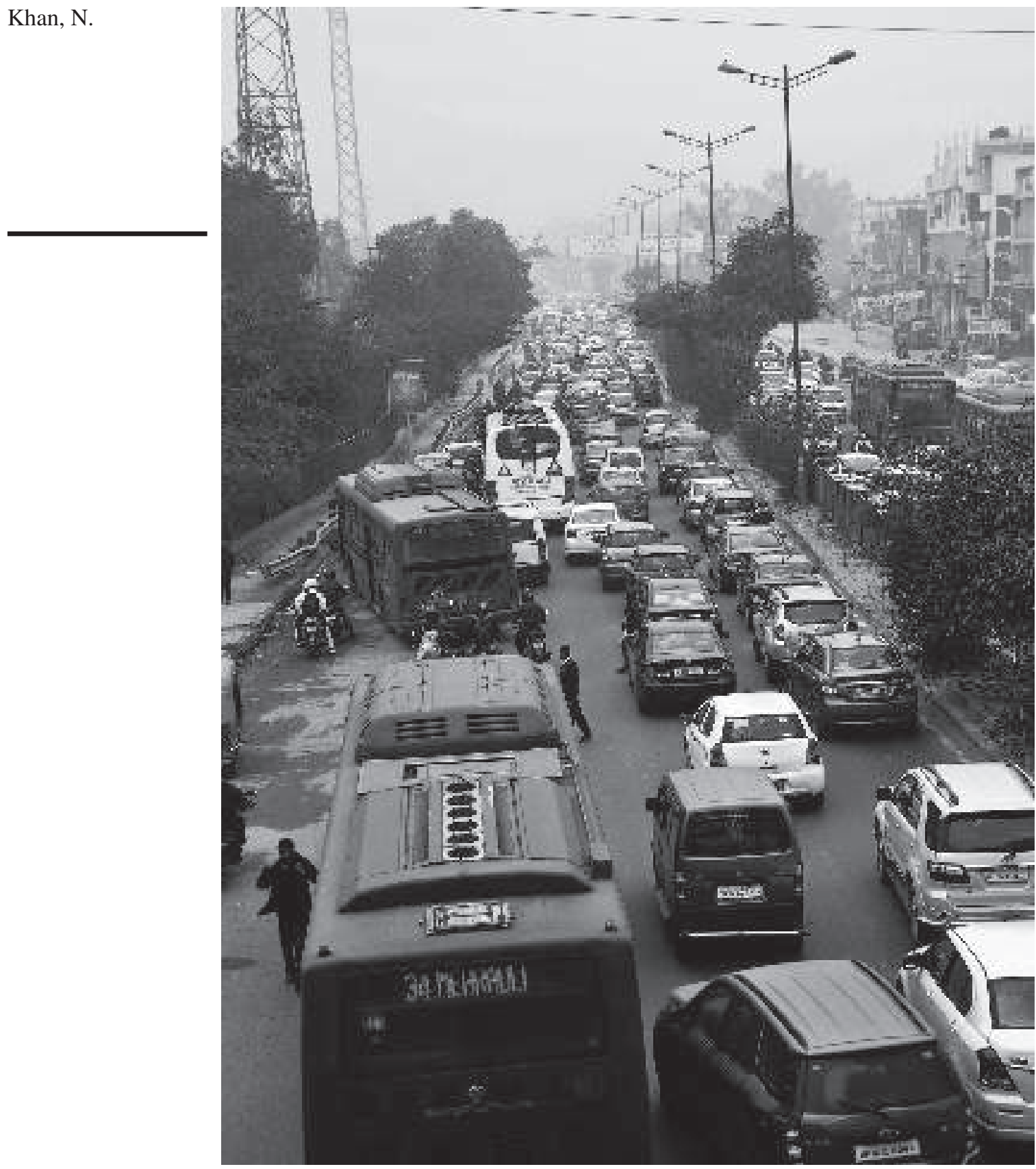

Figure 1 Traffic Jams are usual occurances on the roads in Delhi (Image source: Author) 


\section{SCENARIO OF TRANSPORTATION IN DELHI}

The road transport infrastructure of Delhi is huge. Such is the emphasis given to the planning of roads that the total area covered by the roads is almost $21 \%$ of the city. The total length of roads in Delhi is $28508 \mathrm{~km}$ comprising of 388 km of National Highways (DDA, 2007).

There are more than 40 types of modes of road transport existing in the city, comprising of Buses, RTV, Taxis, Auto Rickshaw, Gramin Seva, Electric Rikshaw, and Cycle Rikshaw as public mode of transportation. Cars and TwoWheelers comprise of major parts of private mode of transportation (Rao, Kanchan and Nanda) (Fig. 2). The Delhi Metro is the city's Mass Rapid Transit System. Buses constitute the major mode of public transportation, with $60 \%$ commuters favouring this system. There are about 6000 buses in the city run by the Delhi Transport Corporation (DTC) and some private operators on 773 routes with 2500 bus-stops (Delhi Transport Corporation). Apart from the DTC buses, there are school buses and other chartered buses ferrying school children and office goers. The RTVs are mini-buses operated on internal roads and acting as feeders to the main bus routes and metro stations. Most RTVs are operated by private transporters. Similar to the RTV, the 'Gramin Seva'

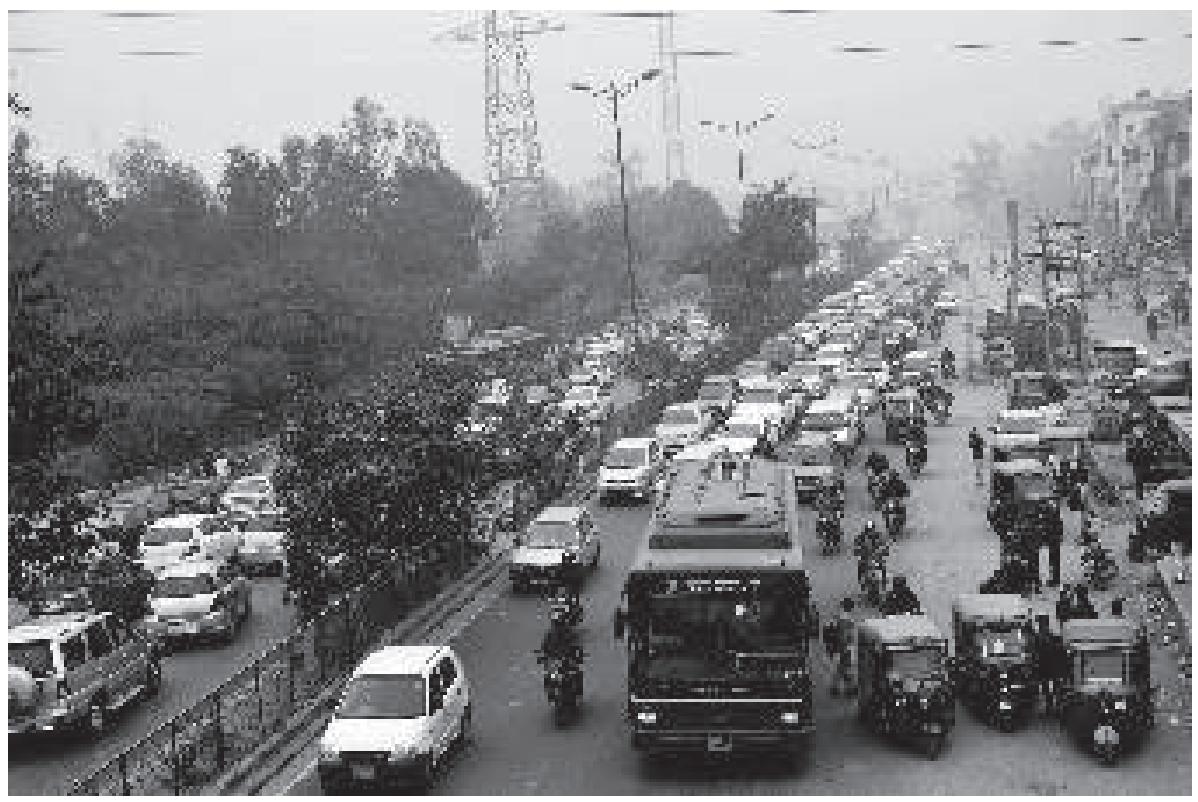

Figure 2: Cross-Section of road traffic in Delhi showing different modes of Transportation.
Augmenting the Transit Capacity of Delhi by Renewal of the Sub-Urban Railway 
Khan, N.

is a feeder service of vans ferrying passengers on internal roads and linking main roads and metro stations. Cycle Rickshaws operate inside the residential colonies, with Electric Rickshaws as a recent addition, and ferry commuters on short distances. Taxis are operated by various radio-cab services and private transporters. Auto-Rickshaws operate throughout the city and ferry passengers on a non-sharing basis. A very large number of commuters - about $30 \%$ - use private vehicles, i.e., their cars and two-wheelers, in the city (Department of Planning, Government of NCT of Delhi, 2013).

Despite the huge network of roads and the many additions of flyovers, underpasses, etc., a long term solution has not yet been reached to manage and ease the traffic situation of the city. Even, the Bus Rapid Transit system has failed to achieve projected results (CRRI, 2002).

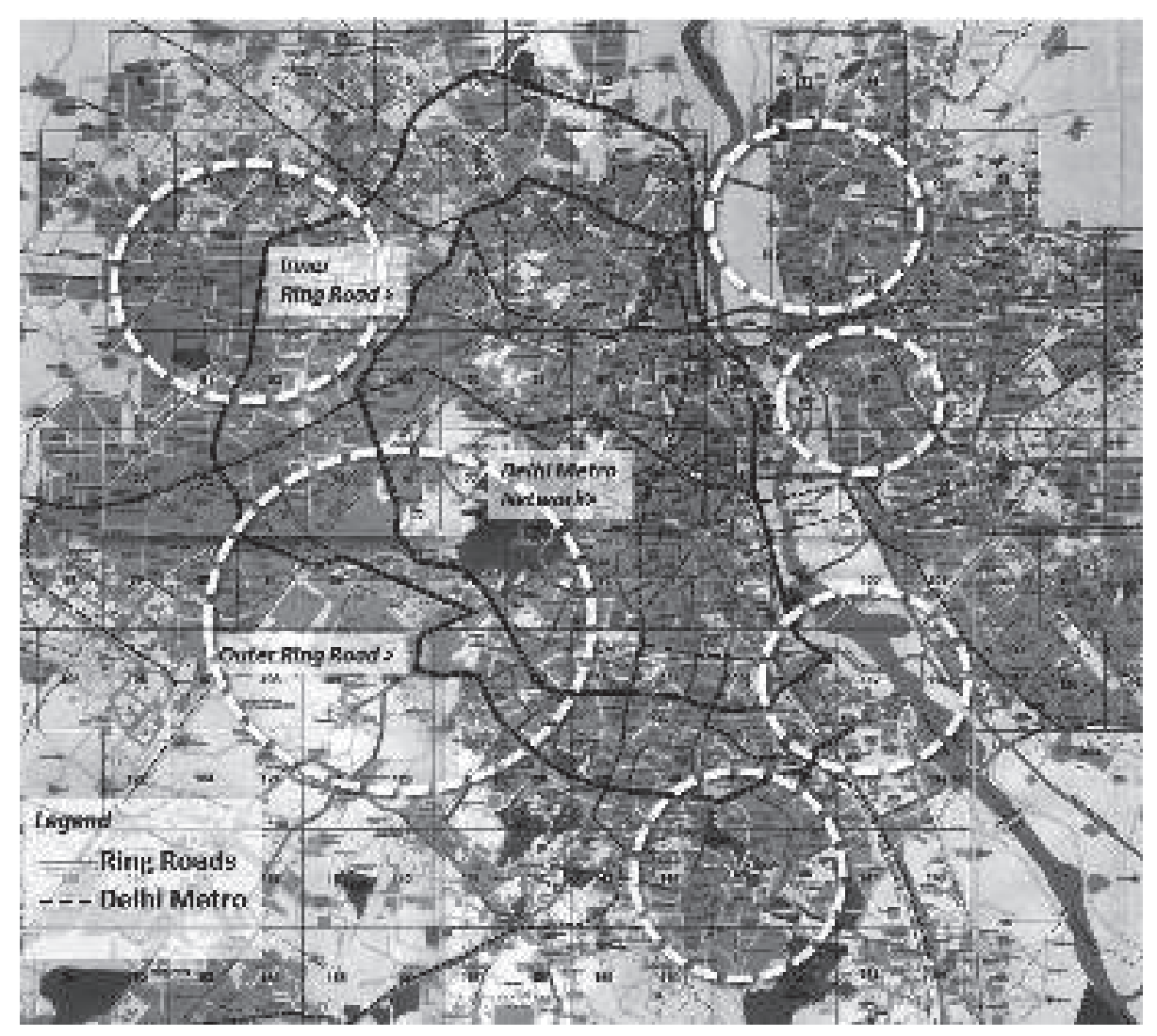

Figure 3: Transport Network in Delhi. Metro Routes are shown in dash lines. Ring Roads are shown as solid lines. Regions out of the reach of Metro Network are shown in Circles. (Image source: Author; Base Map- Eicher Delhi City Map). 


\section{URBAN FORM AND STRUCTURE OF THE CITY'S TRANSPORT INFRASTRUCTURE}

Delhi has acquired a 'nuclei and sprawl' like urban form as a result of a continuous ring-like expansion, while Mumbai and Kolkata have emerged as linear cities due to limited land availability. The structure of the transport network in both Mumbai and Kolkata is bi-directional, where the primary mass transport service is supported by the lateral feeder services. Clearly, in the case of Mumbai as well as Kolkata, the transportation structure compliments the form of the city, unlike the situation in Delhi.

Delhi, being a city that has spread in both length and breadth, portrays a spider-web like transport network, with multidirectional traffic and many intersections. The 'Inner Ring Road' is the lifeline of Delhi. It is $51 \mathrm{~km}$ long road, with more than 25 flyovers and grade separators, taking the form of a loop to connect major areas of Delhi. The 'Outer Ring Road' is a result of the urban expansion of Delhi along and outside the Inner Ring Road. It runs concentric to the Inner Ring Road, both the rings being connected with radial roads at intervals (Fig. 3). The ring roads are major arterial roads plying lacs of vehicles per day (Public Works Department Delhi).

The non-linear form of Delhi demands a larger transport infrastructure to reach various parts of the city. Moreover, the transport network needs to be interconnected at various places for efficient accessibility.

The structure of Delhi Metro routes, on the other hand, is contradictory to the form of the city. While the road network, as discussed earlier, is a spider web structure embedded in the form of the city, the Metro is planned as a linear network with multiple branches acting as complimentary routes to the road network. This has resulted, of course, in better connectivity and reduced travel time between various parts of the city which were otherwise linked by the large network of roads

\section{SCENARIO OF DELHI METRO}

The only silver lining in the transportation of Delhi is the Delhi Metro, which is fast becoming the preferred mode for commuting. The average daily ridership has reached 2.7 million on this network that covers 193 kilometers on six lines with 140 stations. The Delhi Metro runs 2700 trips daily with a frequency of about 2.5 to 3 minutes (Delhi Metro Rail Corporation Ltd.).

However, whereas on the one hand the Delhi Metro is running overcrowded; on the other hand its effectiveness in reducing substantial volume of vehicles on roads remains doubtful. The major reasons for the inefficiency of the Delhi Metro are lapses in the Multi-Modal Integration (MMI) and Last
Augmenting the Transit Capacity of Delhi by Renewal of the Sub-Urban Railway

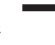



only within the close proximity of its corridors. The parts of the city away from the Metro routes continue to generate substantial road traffic.

For example, in order to travel from Okhla to Gurgaon one has to take metro towards North on the Violet Line to Central Secretariat and then change for Gurgaon on Yellow Line towards South, doubling the travel distance, time and fare. Similarly, Metro travel from Sarita Vihar to Noida, covers 31.2 km., taking 56 minutes, crossing 26 stations with 02 interchanges, paying an amount of Rs. 27.00. The same travel by road is covered in only $9.4 \mathrm{~km}$. in about half time and fare (Delhi Transport Corporation; Delhi Metro Rail Corporation Ltd.).

\begin{tabular}{|l|l|l|l|l|l|}
\hline Trip: Okhla to HUDA City Centre(Gurgaon) \\
\hline Mode & Distance (Km) & Time (Min) & Stations & Fare (Rs) & Interchange \\
\hline By Delhi Metro & 39.9 & 66 & 29 & $29 /-$ & 01 \\
\hline By Bus & 34.2 & 72 & - & $25 /-$ & 01 \\
\hline By Car/ 2W & 34.2 & 48 & - & - & - \\
\hline Trip: Sarita Vihar to Noida Sector 18 & Time (Min) & Stations & Fare (Rs) & Interchange \\
\hline Mode & Distance (Km & Tele & 26 & $27 /-$ & 02 \\
\hline By Delhi Metro & 31.2 & 56 & - & $15 /-$ & 01 \\
\hline By Bus & 9.4 & 28 & - & - & - \\
\hline By Car/ 2W & 9.4 & 20 & - & \\
\hline
\end{tabular}

Table 1: Comparison of Trips using Delhi Metro and Road based Transport in Delhi.

As evident from the two cases, the discontinuities in the existing metro routes are the primary reason for generation of traffic on roads. As shown in Figure 3, such gaps exist in many parts of the city. Overcrowding of the metro during peak hours is also a reason for people preferring to use their cars and two-wheelers on the road. People seeking comfort during travel desist from using Metro due to overcrowding. The efficiency of the Metro will be enhanced by the future expansion of the existing network in upcoming phases, along with implementation of effective multi-modal traffic integration. The issue of overcrowding can be addressed by increasing the number of coaches and the frequency during peak hours. 


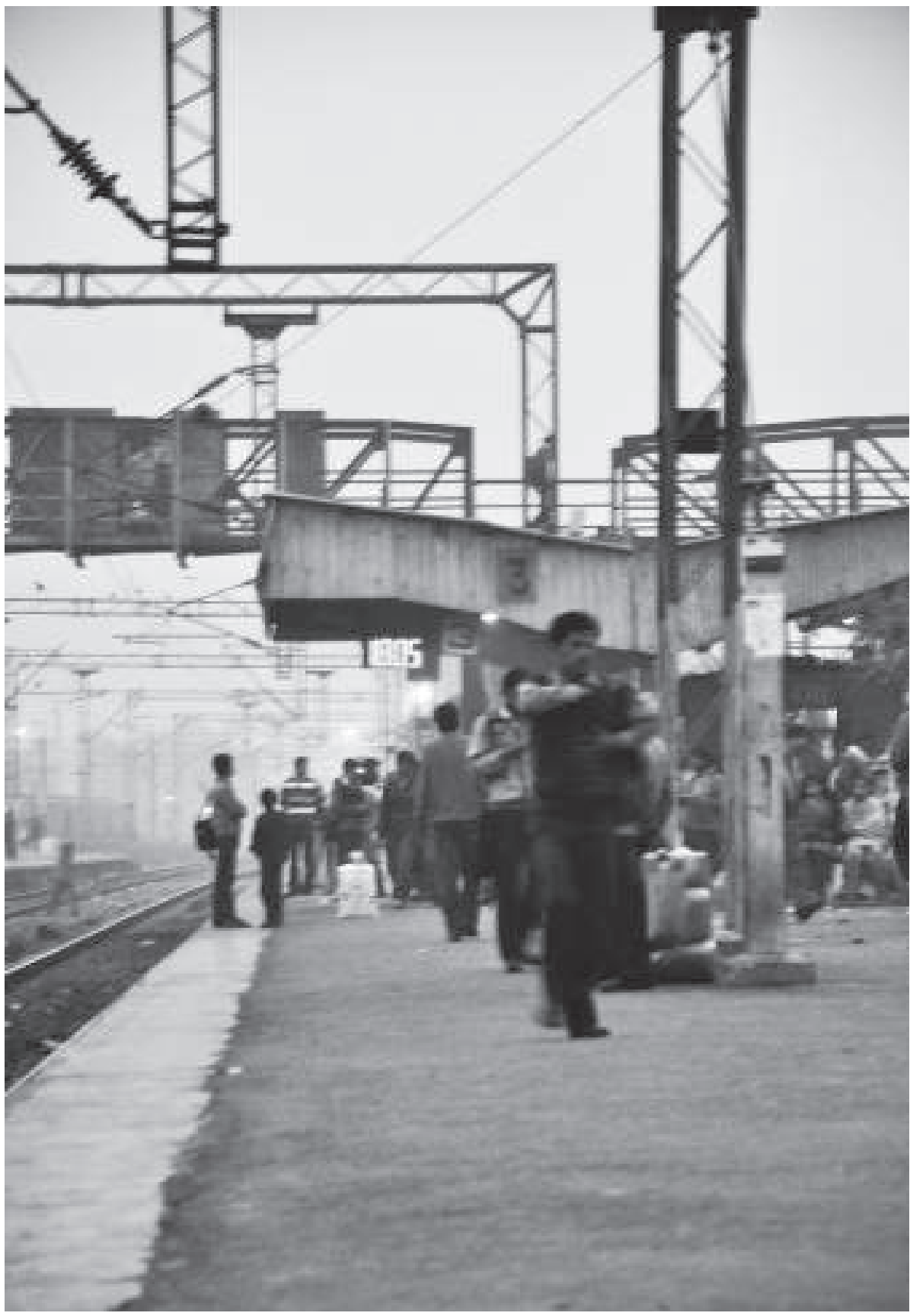

Augmenting the Transit Capacity of Delhi by Renewal of the Sub-Urban Railway

Figure 4: Passengers waiting for Sub-Urban Train during peak hour in the evening. (Image source: Author). 


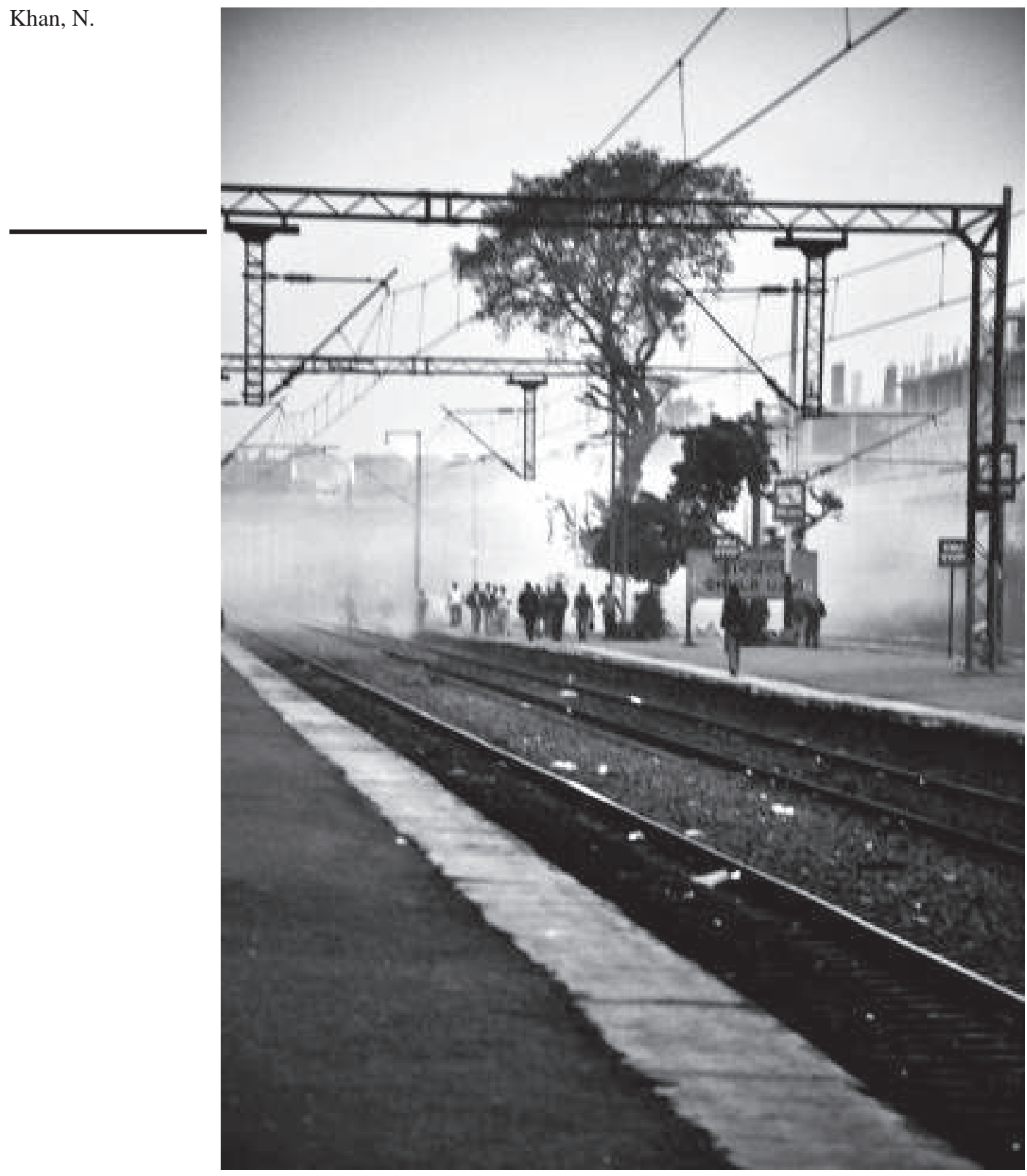

Figure 5: Few passengers use the Sub-Urban Railways (Image source: Author). 


\section{THE CASE OF THE SUB-URBAN RAILWAY}

The infrastructural additions have failed to find a solution to the transportation crisis in Delhi. Ironically, the inherent potential of the already existing SubUrban Railway has been completely ignored by the planners and other authorities. Delhi's Sub-Urban Railway was planned in 1975 for the goods train to bypass the main train routes. During the 1982 Asian Games, the Sub-Urban Railway was upgraded for passenger services. However, it never became the preferred travel mode among the city's rising population due to many factors, but primarily the neglect at the hands of authorities and its non-integration with the other modes of transportation (Sweta Dutta, 2011) (Fig. 4 and 5).

While, road-based transportation was constantly developed; the frequency of EMU trains ferrying passengers on the track remained as long as 60-90 minutes, making it a slow and non-preferred mode of commutation. There are only 12 trips run per day by Indian Railways, 6 in clockwise direction and 6 anticlockwise direction. Most of the trips run empty and daily ticket sale is merely around 1500 . Most of the passengers are commuters from the

neighboring cities of the NCR (Sweta Dutta, 2011) (Fig. 6).

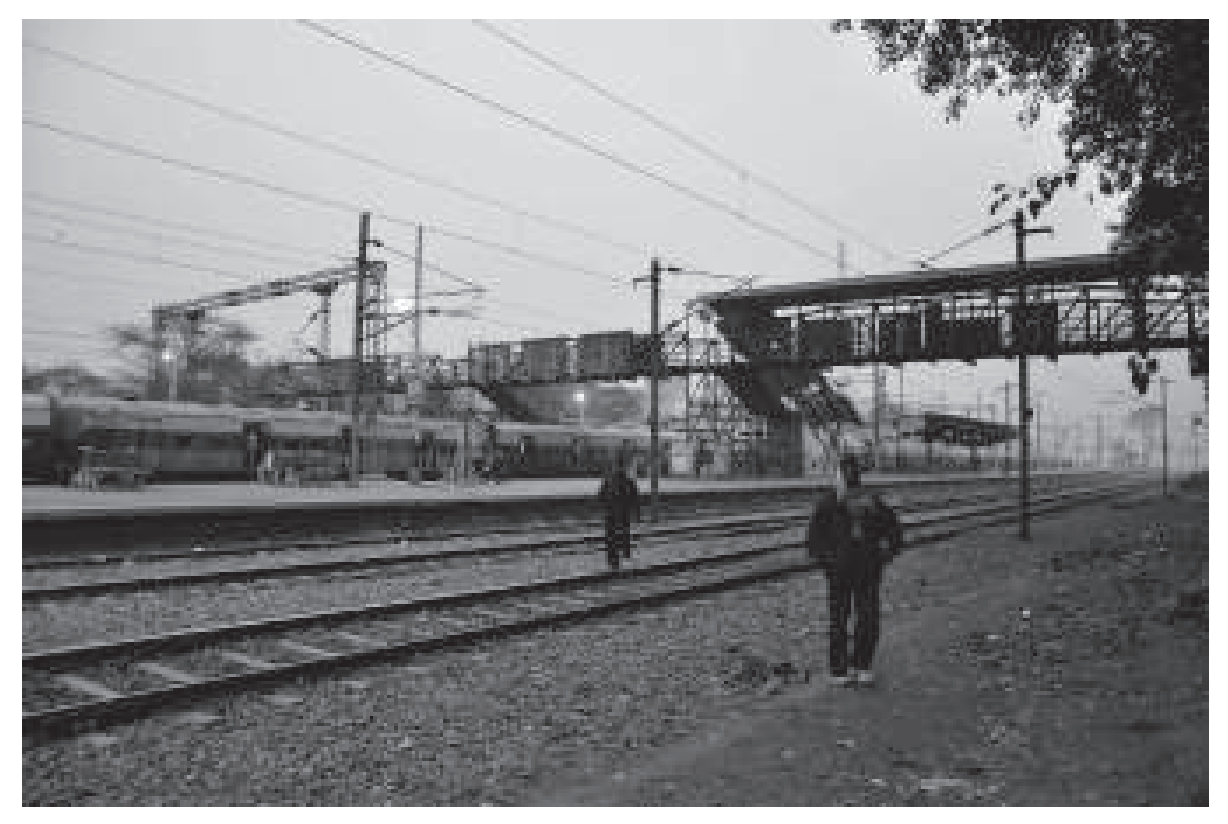

Figure 6: A Sub-Urban Train at Okhla Station (Image source:Author)
Augmenting the Transit Capacity of Delhi by Renewal of the Sub-Urban Railway 
Khan, N.

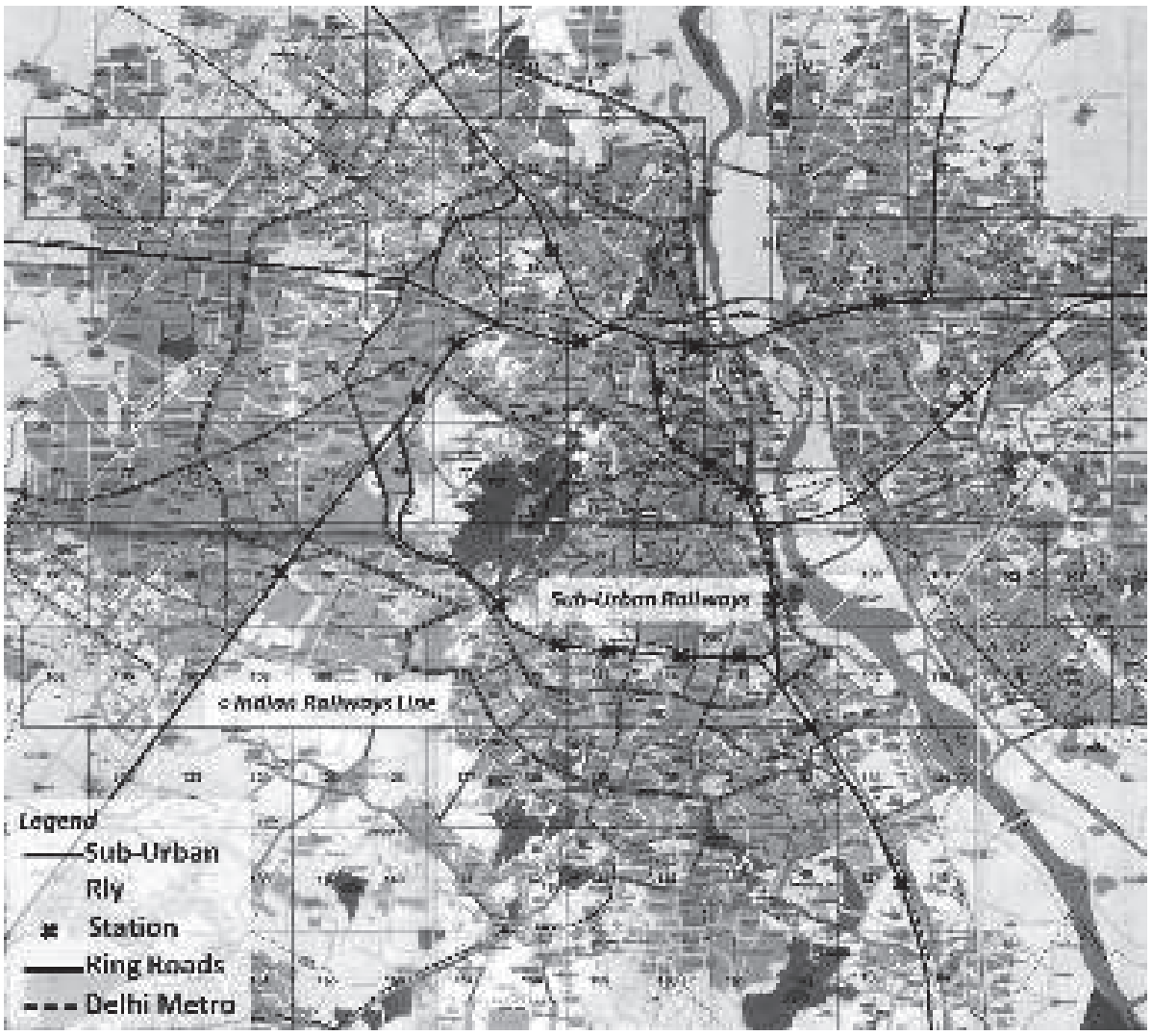

Figure 7: Map of Delhi showing network of Sub-Urban Railways. (Image source: Author; Base Map- Eicher Delhi City Map).

In the present situation, the rapid expansion of Delhi has brought the SubUrban Railway into the core of the settlement with many important residential, institutional, commercial and recreational spots such as Hazrat Nizamuddin, Okhla, Safdurjung, Lajpat Nagar, Dilli Haat, Chanakyapuri, Pragati Maidan, Sadar Bazar and, New Delhi falling on the circular rail track. However, these stations are not easily accessible or visible in the present state. Moreover, the Sub-Urban Railway, due to its location and circular layout, has the capacity to act both as complimentary and supplementary to the existing transport infrastructure of the city. It can play an important role in the integration of the Metro and Bus Service (Fig. 7). Operating on electricity, the Sub-Urban Railway is also an eco-friendly mode with minimal impact on the much deteriorated environment of Delhi. 


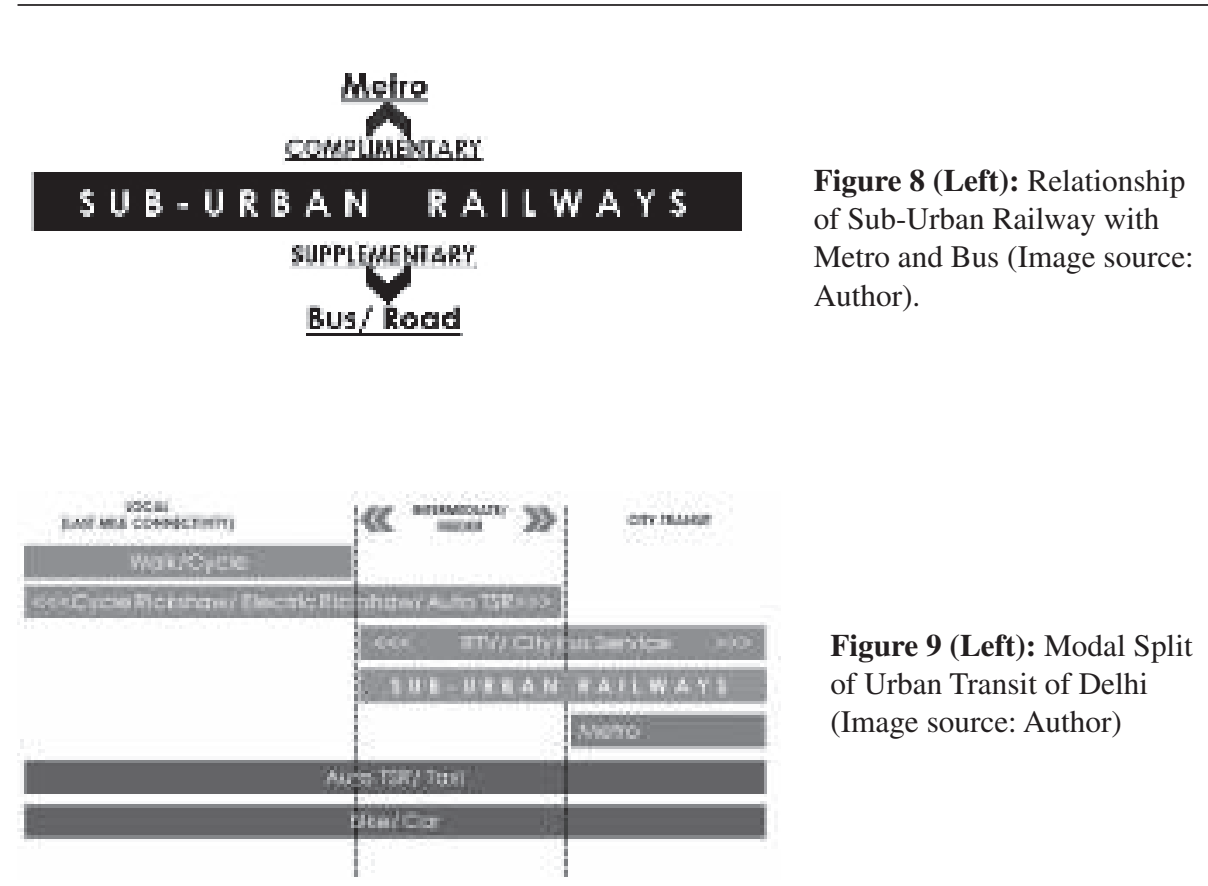

Where Mumbai commutes primarily on its Local Rail system, also known as the Mumbai Life line, Delhi never developed the potential of this existing resource. In the present scenario, with a small investment, the Sub-Urban Railway can be upgraded into an integrated transit system with multiple benefits. Similar to Mumbai's Local, Sub-Urban Railway of Delhi can carry large numbers of commuters in a safe, convenient and economical manner.

\section{MODAL RELATIONSHIP AND HIERARCHY OF SUB-URBAN RAILWAYS}

The Sub-Urban Railway is a unique level in the Modal Hierarchy of Transport Infrastructure of Delhi. Based on the locations and structure of the Sub-Urban Railway network with respect to Ring Roads and Metro Routes, it can be deduced that this is the only mode of transport that is supplementary to the Bus-Service and complimentary to the Delhi Metro network (Fig. 8). With this unique relationship the Sub-Urban Railway can be utilized in augmenting the road-based transport capacity. Since Sub-Urban Railway is a mass transit mode, it will support substantial passenger carrying capacity. The reduction in the road-based transport, especially buses, shall be significant (Fig. 9). 
Moreover, the Sub-Urban Railway can act as a feeder service to the Metro by connecting its different routes. The circular layout of the Sub-Urban Railway can provide shorter and quicker connections to the different Metro routes in the radial layout. This may rule out the need of newer Metro routes for the purpose. The Sub-Urban Railway connects with the neighboring cities of Delhi, thus, an effective integration of this system with other modes of transportation will also make inter-city commuting convenient.

\section{PROPOSALS}

Based on discussion in the preceding paragraphs, the following strategies for augmentation of the transit capacity may be proposed for the Sub-Urban Railway of Delhi.

Revive: The Sub-Urban Railway should be revived as a mode of urban transportation in Delhi. It should be developed as an alternative to Road Transport and as a Feeder/Connector to the Delhi Metro.

1. Upgrade: The existing infrastructure of the Sub-Urban Railway should be upgraded for the purpose. The stations should be made easily accessible and visible. The provisions of barrier-free environment and automatic ticketing should be incorporated for the convenience and seamless interchange of the commuters.

2. Augment: The frequency of the trains on the route should be increased to augment the carrying capacity and reduce the waiting time for the commuters.

3. Enhance: Initiatives to generate awareness about the Sub-Urban Railway should be taken to make it popular with commuters. As many of the stations are located in the vicinity of heritage and recreational sites, cultural or tourism special trains could also operate during non-peak hours or during holidays.

\section{CONCLUSIONS}

Delhi has evolved as a complex and complicated Mega-City. The solutions to the problems of Delhi have to be indigenous and innovative. In the specific case of its Urban Transit, having a network of multiple modes with seamless integration will improve the carrying capacity and effectiveness of the system. Sub-Urban Railway is a mode of transportation which may be employed to fill the modal gap existing in the present system. The infrastructure is already in place and can be renewed with very little investment to substantially augment the transit capacity of Delhi. 


\section{REFERENCES}

[1] CENTRAL ROAD RESEARCH INSTITUTE. (2002). Evaluation of Delhi Roads for Maintenance and Rehabilitation Strategies, Final Report. New Delhi: CRRI.

[2] DELHI DEVELOPMENT AUTHORITY. (2007). Master Plan of Delhi 2021. New Delhi: DDA.

[3] DELHI METRO RAIL CORPORATION LTD. Available from: http://www.delhimetrorail. com. n.d. http://www.delhimetrorail.com/about_us.aspx [Accessed: January 05, 2015].

[4] DELHI TRAFFIC POLICE. Available from: https://delhitrafficpolice.nic.in. n.d. https:// delhitrafficpolice.nic.in/about-us/statistics/ [Accessed: January 05, 2015].

[5] DELHI TRANSPORT CORPORATION. Available from: http://dtc.nic.in. n.d. http://dtc.nic. in/dt3.htm [Accessed: December 24, 2014].

[6] DEPARTMENT OF PLANNING, GOVERNMENT OF NCT OF DELHI. (2013). Economic Survey of Delhi. New Delhi: Government of NCT of Delhi.

[7] PUBLIC WORKS DEPARTMENT DELHI. Available from: https://www.pwddelhi.com. n.d. https://www.pwddelhi.com/Images/RoadMap.jpg [Accessed: January 05, 2015].

[8] RAO, P. I, KANCHAN, P.K., and NANDA, P.K. (2006). GIS Based Maintenance Management System (GMMS) For Major Roads Of Delhi. Available from: http://www.gisdevelopment. net/proceedings/mapindia/2006/transportation/mi06tran_200.htm [Accessed: December 25, 2014].

[9] DUTTA, S. (2011). Changing Delhi map makes Ring Railway redundant. The Indian Express [Online] 22 ${ }^{\text {nd }}$ February. Available from: http://archive.indianexpress.com/news/changingdelhi-map-makes-ring-railway-redundant/752994/0 [Accessed: December 28, 2014].
Augmenting the Transit Capacity of Delhi by Renewal of the Sub-Urban Railway 